University of Wollongong

Research Online

Faculty of Social Sciences - Papers (Archive) Faculty of Arts, Social Sciences \& Humanities

2015

From incremental change to radical disjuncture: Rethinking everyday

household sustainability practices as survival skills

Christopher R. Gibson

University of Wollongong, cgibson@uow.edu.au

Lesley M. Head

University of Wollongong, Ihead@uow.edu.au

Chontel A. Carr

University of Wollongong, ccarr@uow.edu.au

Follow this and additional works at: https://ro.uow.edu.au/sspapers

Part of the Education Commons, and the Social and Behavioral Sciences Commons

Research Online is the open access institutional repository for the University of Wollongong. For further information contact the UOW Library: research-pubs@uow.edu.au 


\title{
From incremental change to radical disjuncture: Rethinking everyday household sustainability practices as survival skills
}

\begin{abstract}
Households within affluent countries are increasingly prominent in climate change adaptation research; meanwhile, social and cultural research has sought to render more complex the dynamics of domesticity and home spaces. Both bodies of work are nevertheless framed within a view of the future that is recognizable from the present, a future reached via socioecological change that is gradual rather than transformative or catastrophic. In this article, we acknowledge the agency of extreme biophysical forces and ask what everyday household life might be like in an unstable future significantly different from the present. We revisit our own longitudinal empirical research examining household sustainability and reinterpret key results in a more volatile frame influenced by political ecological work on disasters. We seek to move beyond incremental to transformative conceptions of change and invert vulnerability as capacity. Vulnerability and capacity are contingent temporally and spatially and experienced intersubjectively. The resources for survival are ultimately social and therefore compel closer scrutiny of, among other things, household life.
\end{abstract}

\section{Keywords}

household, everyday, rethinking, skills, disjuncture, survival, radical, change, incremental, practices, sustainability

\section{Disciplines}

Education | Social and Behavioral Sciences

\section{Publication Details}

Gibson, C., Head, L. \& Carr, C. (2015). From incremental change to radical disjuncture: Rethinking everyday household sustainability practices as survival skills. Annals of the Association of American Geographers, 105 (2), 416-424. 


\title{
From incremental change to radical disjuncture: rethinking everyday household sustainability practices as survival skills
}

\author{
Chris Gibson, Lesley Head and Chantel Carr \\ Australian Centre for Cultural Environmental Research, University of Wollongong
}

\begin{abstract}
Households within affluent countries are increasingly prominent in climate change adaptation research; meanwhile social and cultural research has sought to render more complex the dynamics of domesticity and home spaces. Both bodies of work are nevertheless framed within a view of the future that is recognizable from the present, a future reached via socioecological change that is gradual rather than transformative or catastrophic. In this article we acknowledge the agency of extreme biophysical forces, and ask: what might everyday household life be like in an unstable future significantly different to the present? We revisit our own longitudinal empirical research examining household sustainability, and reinterpret key results in a more volatile frame influenced by political ecological work on disasters. We seek to move beyond incremental to transformative conceptions of change, and invert vulnerability as capacity. Vulnerability and capacity are contingent temporally and spatially, and experienced intersubjectively. The resources for survival are ultimately social, and therefore compel closer scrutiny of, among other things, household life. Key Words: adaptation, capacity, climate change, transformation, vulnerability.
\end{abstract}


Households in the affluent West are increasingly present in sustainability discourse, in hazards management, and in visions of how to mitigate and adapt to climate change (Reid, Sutton, and Hunter 2009; Waitt et al. 2012; Eriksen 2013). At the same time, social and cultural research has sought to trouble the household as a bounded or stable entity - revealing complexities of family life and intersections between people, nature, objects, work and practices within and beyond the home (Blunt and Dowling 2006; Gregson 2007; Pink 2012; Cox 2013). The microscopic details of household life matter enormously: they can be conceived as the cellular activity fuelling climate change, and shaping preparedness, while questions of family, relationships and livelihood are what most people care and worry about.

Meanwhile in research on preparedness for hazards and emergencies, the household is one scale at which to observe vulnerability and/or resilience. Capacities to respond to severe disruptions are shaped by underlying inequalities and social differences (Sevoyan et al. 2013), and complex placeand path-dependent factors including social cohesion and community networks (Prior and Eriksen 2013). A related, critical literature also considers the security and risk management apparatuses increasingly governing citizens amidst anticipated volatility (Anderson 2010; Methmann and Rothe 2012). Recent efforts have sought to link some of these otherwise disconnected threads (Shove and Walker 2010; Morrice 2013; Brown 2014), but by and large, the two broad bodies of work - political ecologies of hazards, and cultural geographies of home and household sustainability - exist in separate orbits. This article seeks to bring them together based on the premise that in the affluent West, where per capita carbon emissions are highest, the household is a key scale to envisage future transformations in socioecological relations.

Our contention is that much of this work, including our own, has nevertheless been overtaken by escalating events, and is framed in ways that consequently now appear limited. Here, we seek to consciously unsettle normative framings of such established precepts as resilience and sustainability, in light of anticipated extremity and the likelihood of forced and unstable future socioecological relations rather than gradually planned transitions. We seek to bring cultural geographical work on 
households into conversation with some of the scenarios invoked by climate change science, and with critical political ecologies of disasters.

Research on adaptation, vulnerability, preparedness and resilience has emphasized urban and community scales, especially in the developing world, where populations are recognized to be particularly vulnerable to climate change (Adger et al. 2003; Bulkeley and Tuts 2013). Notwithstanding Fordham's call nearly two decades ago for disaster research to consider the private/household domain in the developed world as “a legitimate object of research” $(1998,126)$, analyses are still less advanced in the developed than in the developing world (Head et al. 2011), and the internal complexities of home life, families, gender and emotion are only beginning to be appreciated (Proudley 2008; Caruana 2010; Whittaker et al. 2012; Eriksen 2013; Morrice 2013). This article accordingly focuses on developed world households as one important, but neglected site of analysis.

Meanwhile, the cultural literature on households has other conceptual limitations. Nuanced ethnographic accounts are the norm (e.g. Gregson 2007; Pink 2012), but of the relativities and contingencies of the present -- a framing that makes sense in an anthropological mode of inquiry, but that inadvertently eschews abilities to conceive future climatic extremity. What if we acknowledge the agentic capacities of nonhuman others - including the climate assemblage itself - to produce more catastrophic results? The household literature may not have acknowledged such agency, but the scientific literature on climate change has (although not in exactly these words). What might everyday household life be like living on a $4^{\circ} \mathrm{C}$ hotter earth? What will happen to the notion of the everyday when haunted by the specter of biophysical catastrophe and associated economic hardship, or when it routinely incorporates extreme weather events?

With climate change up until now viewed as somewhere "over the near horizon,” the emphasis has been on, inter alia, identifying policies for mitigation and adaptation, predicting unequal impacts on sections of society, identifying vulnerable populations, and determining policies to increase potential 
resilience (Brown 2014). All such actions foresee futures in specific ways that shape the style of investigations and policies - anticipating extremity, but rarely catalyzing "exceptional extraordinary measures” (Methmann and Rothe 2012, 323). Application of concepts including “resilience,” “vulnerability” and “adaptation” has proceeded without due acknowledgement of disciplinary and epistemological traditions that shape interpretations (Miller et al. 2010), instead advancing a “governmental scheme of risk management” (Methmann and Rothe 2012, 323) that has the effect of maintaining the status quo. The same could be said of "sustainability" in the household realm (Davidson 2010). Lurking are desires that seem increasingly impossible: to return back to a stable, Holocene condition (Hulme 2010); to somehow adapt gradually to changes in ways that obviate discomfort.

In what follows we seek to rethink climate change adaptation and sustainability agendas at the household scale, and through a more catastrophic lens. We first move from incremental to transformative conceptions of change, and second invert concepts of vulnerability and capacity. Transformative change acknowledges that things cannot proceed as present, and that a more disruptive framing enables scope for conceptions of uncertain futures. Likewise, vulnerabilities inverted open up possibilities to identify creative abilities and capacities.

The household is, we emphasize at the outset, not a neatly bounded or even a preeminent scale at which to pursue this agenda. But the household is a critical scale at which people encounter disruption and adjust amidst the dilemmas of everyday life (Eriksen 2013). In this important space, we argue, it is possible to observe practices that have been, within incrementalist logic, viewed as proenvironmental or sustainable, but which within a more volatile framing can be more meaningfully interpreted as survival capacities.

We then illustrate by briefly revisiting our own empirical findings on households - already communicated previously within a discourse of sustainability and climate change (Gibson et al. 2013) - to excavate insights for survival. We discuss what households worry about the future, and what 
kinds of creativity may be needed for volatile futures. While the household is the focus we hope that, in the context of this special issue, the rethinking of vulnerability and capacity will have relevance to wider debates.

\section{From incremental to transformative change}

Many of the biophysical processes generating a changed climate are already locked in (Solomon et al. 2009). We are looking at forced change and the need for responses to unpredictable events, rather than a period of controlled, staged adjustment enabling continued growth and prosperity (O’Neill and Handmer 2012). There are profound challenges here for the whole of society. The ground is shifting rapidly -- it is not long since adaptation was considered taboo because it implied defeatism against the possibility of mitigation (Pielke et al. 2007).

From within the adaptation community come amplified warnings about the speed and magnitude of change, and of uncertainty escalating in ways that make any sense of gradualist change impossible (Adger and Barnett 2009; Kates, Travis, and Wilbanks 2012). Incrementalist approaches limit capacity to acknowledge the power of individual climatic events to throw things into disarray (O’Neill and Handmer 2012). Transformational rather than incremental change appears essential (Park et al. 2012), referring not only to the possibility of a $4^{\circ} \mathrm{C}$ warmer world (Stafford Smith et al. 2011), but also to the increased level of surprise associated with rapid change in complex systems. There are nevertheless tensions. The scientific community increasingly recognizes the need for transformative change. Australia’s federally funded Commonwealth Scientific and Industrial Research Organization (CSIRO) recently argued that alternative governance arrangements might become necessary, in ways that are clearly challenging for politicians to hear (Head et al. 2013). Decision-makers will have to "hedge bets," knowing some will turn out to be wrong (Stafford Smith et al. 2011).

Yet, transformation will need more than accurate decision-making or modeling and predicting of uncertainty. Significant transformations require multiscaled governmental responses, accommodative 
social contexts, and deep challenges to the economic status quo (Bulkeley and Moser 2007; Agrawal 2010; Kates, Travis, and Wilbanks 2012). And yet there are also societal limits to adaptation prospects shaped by values, ethics, knowledge, and culture (Adger et al. 2009). Vulnerability is multivalent, path-dependent, spatially heterogeneous and more difficult to model forward than backwards (Adger 2006; Preston 2013). Preparedness is refracted through complex filters of social difference, including gender in the context of domestic spaces (Proudley 2008; Eriksen 2013), and within migrant, indigenous and socioeconomically disadvantaged communities (Sevoyan et al. 2013). Application of such concepts as vulnerability and resilience has been criticized for downplaying capitalist social relations that produce uneven geographies of exposure to risk (MacKinnon and Derickson 2013), and for neglecting the emotional work of trauma recovery (Whittle et al. 2012). Failing to engage with advances in social and cultural research results in unwitting essentializing of axes of inequality and difference, and neglecting how race, class and gender intersect (Cupples 2007; Eriksen 2013). Many such experiences are galvanized within household life.

Moreover, governed populations react unpredictably to collapsing economic and social systems. Decision-making frameworks necessarily need both long and short lead times while acknowledging uncertain lag effects between decisions and consequences (Stafford Smith et al. 2011), all of which risks social unrest, and unsettles attempts to quantify future national, community or household vulnerabilities. Recent experiences after the financial crisis show that dramatic political and economic shocks are already disrupting emotional ties and relationships in unpredictable ways (Gorman-Murray 2011). Upheaval and dissent is discomforting, but may also be more truly transformative (Pickerill and Chatterton 2006). The professionalization of adaptation as a new form of management similarly risks overestimating human control, and privileges elite experts and state agencies in the defining and documenting of vulnerability and resilience (MacKinnon and Derickson 2013) -- again isolating households.

On the flipside, starting with a more urgent, catastrophist framing challenges much of the work on sustainability initiatives and policies for households -- where the aim has been to overcome barriers of 
habitual everyday practice, and transition incrementally to a low-carbon, but still steady-state economy and society. Instead of contemplating what kind of technologies, policies or behavioral changes are needed to reduce energy or water use with minimal impact on living standards, we ask how well households are positioned to respond to as-yet-unknown external forces.

Indeed, in much of the cultural and ethnographic work on households, remarkably little is said of uncontrollable external climate processes, of biospheres as dynamic living systems, or of the prospects of volatile events forcing change suddenly. While there is increasing recognition of morethan-human agency - some of it unwelcome - in households (e.g. Kaika 2005; Power 2005), it is seldom about volatile or calamitous forces. And although this work provides much needed texture to understanding everyday practice within households, there is nevertheless a sense that time rolls on, rather than households being jolted around by forces beyond human control.

\section{Inverting vulnerability and capacity}

A heightened sense of urgency around potential catastrophe invites productive inversions: of vulnerability to risk, and capacity to adapt. In question is what kind of agency is ascribed to households (and other everyday actors) in our framings (Pickerill and Chatterton 2006; Bulkeley and Newell 2010). Research is increasingly patterned into established ways of thinking and modeling vulnerabilities, based on antecedent traditions (Adger 2006; Miller et al. 2010). Income, education, social class, and geographical location (latitudinal position, coastal exposure, remoteness) have become common proxies for vulnerability (Beer et al. 2012). Yet, actions and people who seem resilient or adaptive under a gradualist framing of change may be stranded under conditions of catastrophe -- different skills and capacities may come to the fore.

Ethnographic studies of diverse populations across rural/urban and developed/developing contexts have further demonstrated that beyond social class and cultural difference, capacities to cope and adjust are linked to vernacular and tacit knowledges, social cohesion, sense of place, memories and cultural inheritances (Ford et al. 2008; Strengers and Maller 2012; Eriksen 2013). Developed world 
populations determined as vulnerable using quantitative demographic data are being shown through subsequent qualitative methods to have strong social bonds, from prior experiences of rallying together in response to extreme external forces such as droughts, wildfires and floods (Beer et al. 2012). As Anderson (2008) argued, seemingly vulnerable low-income rural, households apprehend climate change through shared discourses of endurance, uncertainty, advocacy and local resolve.

Likewise, indigenous peoples globally (including within developed countries) have been identified as the most vulnerable to climate change impacts, and yet household scale research is showing strong potential to cope with climate variability (Altman and Jordan 2008; Ford et al. 2008; Head et al. 2013). Maintenance of extended kinship networks can exacerbate residential overcrowding, but also offsets decreased access to appropriate food and other resources (Altman and Jordan 2008). High degrees of mobility increase possibilities for relocation during or after extreme events, meanwhile being unfairly peripheral to government and civil support paradoxically fuels self-sufficiency (Howitt, Havnen, and Veland 2012). Inverting vulnerability and capacity is thus both an issue of conceptual framing, and a function of the scales, sites and modes of subsequent empirical research.

\section{The Australian households study}

With these thoughts in mind we briefly revisit our own group’s work on household sustainability. Viewed through the lens of rupture and potential chaos, it becomes less about generating sociocultural change and more like how to respond to forced circumstances. A list of what we thought of as sustainability practices becomes, in a more catastrophic headspace, a catalogue of resources for survival. Our empirical work, in an Australian industrial region with strong working class history and identification, combined a survey of 1465 households, and over 200 ethnographic interviews, including a longitudinal study of a core group of 16 households (Gibson et al. 2013). ${ }^{1}$

A first phase of statistical work from the survey suggested that, contrary to common assumptions, the households doing more of the "sustainability work" in our sample were low-income rather than affluent (Waitt et al. 2012). They were living in detached homes rather than apartments, and were families headed up by women. Households participating in subsequent ethnographic interviews 
reflected this mix. They were green-leaning in environmental views, though diverse in typology, including single person, extended family, same-sex couples and non-familial households. Many were low-income families, including retired couples surviving on minimum government pensions. A vast majority brought with them a concern for unknown ecological futures, with only one household, a retired couple, explicit in their skepticism of climate change science. Revisiting our findings, it becomes clear that our understandings of household capacities and assemblages of wider forces must be made more complex.

\section{Transformation}

Our households have acute insights into how the future might look different, but cannot see how to get there, except that it might need drastic change. Many expressed frustration with present political inaction; they implicitly critiqued risk management approaches that did little to shift the status quo. Hence for Jen, a retired nurse who lives alone,

The crux of the whole matter is that as long as we can make a quid out of what we do, if the world does crumble in 60 years time we'll fix it when it's really bloody urgent.

That's how I feel the world is handling it at the moment... nobody wants to do anything in case the guy in the next backyard doesn't... it's so pathetic.

Such sentiments were echoed by Bob, a permaculture enthusiast with a strong desire for a "relaxed, simple, family life" who lives with his partner and toddler daughter in a small cottage in a low-income industrial neighborhood:

I think that households need to get more political... But those big changes have to happen to rein in industry... it seems like the same shit has been talked in circles for years, just the same shit over and over.

Households are contemplating extremity, want to see transformational change and are frustrated by the ineffectual nature of incremental approaches.

Households revealed complex understandings of socioecological relations that appear receptive to more dynamic possibilities. Janette is an enthusiastic gardener and a teacher in another low-income 
suburb, who lives with her partner and teenage children in a detached house with extensive food gardens. Her intimate understandings of growing cycles and a nuanced conception of seasonal rhythms suggest survival capacity, rather than socioeconomic vulnerability.

Many households related to cycles of abundance and scarcity across a broad spectrum of practices, but particularly around practices of water use, a heightened but illustrative example from our ethnographic sample, given that interviews were undertaken amidst the worst drought in living memory in Australia. Households demonstrated unexpectedly high degrees of willingness to endure rationing (experienced in the 2000s via compulsory water restrictions), and used creative practices to capture, save and reuse water outside formal regulation. Tom and Joan for example, are a retired couple who have recently downsized their home. Their skepticism towards climate change sits in stark contrast with their enthusiasm for water-saving practices, including coordinating their toilet visits to minimize flushing, and capturing grey water from the shower.

Meanwhile, reduced water use practices did not appear permanently locked in from experience of drought (as the incrementalist behavior change view might hope). But rather than seeing this as a sustainability failure, it alternatively suggests that households are prepared to "go with the flow" and enjoy or even indulge in abundant water in times of excess. The latter seemingly unsustainable practice viewed through an alternative framing shows a stronger sense of connectedness with the resource's materiality, and cycles of abundance and scarcity. Consciousness of cycles of abundance and scarcity was also evident across a spectrum of practices, including gifting, and everyday weather interactions. Households maintain continuities with past ways of interacting with nonhuman nature, without appearing backward looking, signaling everyday capacities to deal with increasingly likely sorts of flux.

\section{Agency and capacity}

People feel complex things about their own agency in this process. One assumption is that household contents are cherished, and that future policies should secure lifestyle maintenance around the 
quantity and newness of material things. The idea of accumulating possessions being a proxy for quality of life is seemingly sacrosanct, yet at the household scale there was real angst about it as well. Paul, for instance, who lives alone in a small public housing unit, was not alone in describing his desires to live more simply, to "be happier with less."

We find broad evidence of evolving and shifting attachments to material possessions. People may not have the agency to prevent catastrophic forces, but enact a kind of agency in reevaluating the significance of material possessions in everyday life. Certainly in Australia, where climate change risk (and associated extremities of flood, fire and drought) is seeping more deeply into everyday life, and where insurance costs are increasingly prohibitive, people are actively imagining losing everything -and many are not so disturbed by that prospect. In a sign of comprehending forced change and extremity in the present, households that acknowledged their lack of power over fire or flood were reevaluating which material possessions matter most - becoming accordingly willing to forsake home contents insurance or give things away to others more needy (cf. Eriksen 2013; Martin 2002). Meanwhile, debate erupted about the loss of other kinds of vital skills and capacities -- those that enable frugal existence in times of constraint and scarcity. Jen is an avid sewer, and talks at length about its usefulness. Peter laments the loss of a disposition to rummage resources together from necessity, and tinkering skills needed to deal with unforeseen change:

It used to be 'she'll be right and we'll fix it up with safety pins and four by two,' or something like that, but that's gone. All of that's long gone.

Janette ruefully describes conspicuous consumption in a new residential estate rapidly developing around her century-old house, disparaging a perceived lack of ingenuity to make do:

They can’t even put a hem up. They can’t sew. They can’t design. They can’t even borrow a book in the library, a lot of them.

In our ethnography, households told abundant stories of making do, and marshaling resources with limited financial security. Sustainability thinking or concern over climate change was rarely present. They were instead frugal practices valued as necessary modes of living -- old-fashioned values from 
working-class and rural upbringings that might be revived as an economic ethics for uncertain futures (Gibson-Graham and Roelvink 2010). Maria for example, foresees an end to wasteful use of domestic electricity, driven by financial pressures, while Amy, a nurse who shares the spare rooms in her house with international students, describes her experience growing up in the remote Northern Territory, where

you learned to make do with what you had. We had electric lights only when the visitors came.

People viewed the stuff within homes differently if forced to imagine it had to last for the rest of their lives. Peter believes this kind of thinking is innate for people of his generation:

I'm a child of the depression of the 1930s... that was what I picked up and my siblings picked up as values. I have a feeling that you use things up 'til they haven’t got much more value and only then you throw them out.

Another potential inversion relates to the accumulation of things within the home, encompassing collecting and storing (Gregson 2007). Large suburban homes that mainstream sustainability discourse would view as energy-inefficient were expedient in the context of survival and the need to store rather than divest useful things (cf. Dowling and Power 2011). A subset of our ethnographic participants were extended family households, many of migrant backgrounds, frequently formed from the fallout of broken marriages or out of necessity to care for sick, but poor, elderly parents. Extended family households needed larger homes in order to house larger numbers of people and things precisely the kind of living arrangements more likely under extreme scenarios (Klocker, Gibson, and Borger 2012). Within extended family households, older family members valued accumulative practices that might be viewed as "hoarding" or as sustainability failures, as necessary for stewardship of still-useful material possessions. Garages were converted into storage zones for things that retained use value, so that those things could be subsequently redistributed among family members. Not only do sustainability practices become survival practices, but also those putatively unsustainable practices that amidst volatility appear to engender both social bonds and responsible stewardship of materials. Such practices, which we were previously drawn to interpret within frames of household 
sustainability, now appear within a more transformative, catastrophic framing as both portentous and propitious.

\section{Conclusions}

We have argued here that the household is a key scale at which to envisage future transformations in socioecological relations in the developed world, and that climate change adaptation and sustainability agendas need to be rethought through a more catastrophic lens. Although households are now largely aware of climate change and its consequences, and are contemplating major upheavals, governments and climate change adaptation policies remain incremental and welded to a static view of the present. Yet householders may be readier to face transformative futures than is often imagined, and different patterns of vulnerability may appear. As Eakin $(2005,1936)$ has argued, more "grounded, locally relevant research" is needed to expose experiences of vulnerability "from the perspective of the vulnerable.” This is especially relevant for households. Catastrophe is already with us, and becoming embedded in everyday Western lives (Anderson 2010). We have long been aware that catastrophe is everyday experience for many people in the world (such as we have seen recently with the Philippine typhoon). We are not so used to experiencing it as part of everyday affluent lives - or indeed researching it within that context.

Where households have figured prominently in political ecological research on disaster vulnerability and preparedness, it has overwhelmingly (and not without good reason) focused on the developing world (Head et al. 2011), and has only recently begun to intersect with cultural and ethnographic work on everyday life, the home, gender and emotions (Eriksen and Gill 2010; Morrice 2013; Eriksen 2013). We have sought to show what kinds of conceptual inversions are possible through bringing political ecological and cultural households research into closer dialogue.

Revisiting our own and others' empirical findings shows that the details of everyday life provide considerable resources to help engage with the challenges of climate change. In particular, this work suggests ways in which ideas of vulnerability and resilience need to be reframed as contingent 
temporally and spatially, and experienced intersubjectively. The household scale of analysis shows some inversions from patterns analyzed at the macroscale. Vulnerability and resilience are cut across by underlying class, intergenerational and cultural differences but also emergent in the moments and spaces of everyday life, including beyond the porous boundaries of the home itself.

There are immense opportunities to revisit the past, and question what kinds of dormant practices could be retrieved anew (Shove 2012). People make sense of dramatic changes and crises, and rekindle capacities to cope, through recalling past experiences (Anderson 2008; Head et al. 2011). Aspects of daily life that make use of diverse "analogue,” pre-electrical, and non-monetary techniques and technologies (line-drying, cycling, walking, sharing, water harvesting, foraging for food), both revisit past experiences and reconnect with biophysical rhythms of abundance and scarcity (cf. McLain et al. 2014). Given conditions are becoming more extreme, modernist expectations of continuities of supply - in food and water, for instance - will presumably give way to seasonal availability and uncertainty. If we let go of the expectation of retaining existing comforts and ubiquitous abundance, then what we think of as failures may be reframed as productive disruptions (Adey and Anderson 2012), or vulnerabilities as capacities. Trauma stimulates resourcefulness and new relationships are built (Eriksen 2013). Meanwhile from the perspective of those households measured as statistically vulnerable, resources for survival, including past values, memories and shared experiences of disruption are evident amongst hardships. Seemingly vulnerable working-class, migrant, indigenous and rural populations have profound capacities to reengage with such resources, or are already doing it out of necessity.

If our brief household examples seem a touch too small scale and not attentive enough to questions of big industry, government and infrastructure, they do nevertheless provide one picture of what survival may look like when the big systems fail. In scenarios where governments or the private sector are unable to meet basic conditions for life, social and community capacity will be critical to survival. And, as the examples above attest, vulnerability may look quite different to how it does now. This is not a rationale for absolving governments or industry of the responsibility to act. Rather we suggest 
that amidst government and corporate intransigence, the resources for survival are ultimately social. Thus when contemplating unthinkable uncertainty and possible socioecological disruptions, we must look deeper, and with less loyalty towards normative framings, to identify contradictions and unheralded survival capacities within households. 


\section{Note}

1. For further detail on method, sampling strategy and representativeness, see Waitt et al. (2012).

\section{Acknowledgments}

We thank Gordon Waitt, Nick Gill, and Carol Farbotko for collaboration on the households research.

Our perspectives benefited from ongoing discussions with Christine Eriksen, Michael Adams, Natascha Klocker, and Stephanie Toole.

\section{References}

Adey, P. and B. Anderson. 2012. Anticipating emergencies: technologies of preparedness and the matter of security. Security Dialogue 43:2, 99-117.

Adger, W. N. 2006. Vulnerability, Global Environmental Change 16, 268-81.

Adger, W. N. and J. Barnett 2009. Four reasons for concern about adaptation to climate change. Environment and Planning A 41, 2800-05.

Adger, W. N., S. Dessai, M. Goulden, M. Hulme, I. Lorenzoni, D. R. Nelson, L. O. Naess, J. Wolf and A. Wreford. 2009. Are there social limits to adaptation to climate change? Climatic Change 93, $335-54$

Adger, W.N., S. Huq, K. Brown, D. Conway, and M. Hulme. 2003. Adaptation to climate change in the developing world. Progress in Development Studies 3, 179-95.

Agrawal, A. 2010. Local Institutions and Adaptation to Climate Change. In: Social Dimensions of Climate Change, ed. R. Mearns and A. Norton. Washington: World Bank, 173-198.

Altman, J. and K. Jordon. 2008. Impact of Climate Change on Indigenous Australians. Canberra: Centre for Aboriginal Economic Policy Research.

Anderson, B. 2010. Preemption, precaution, preparedness: anticipatory action and future geographies. Progress in Human Geography 34:6, 777-798.

Anderson, D. 2008. Drought, endurance and 'the way things were': the lived experience of climate and climate change in the Mallee. Australian Humanities Review 45, 
http://www.australianhumanitiesreview.org/archive/Issue-November-2008/anderson.html (last accessed 27 November 2013).

Beer, A., S. Tually, M. Kroehn, and J. Law. 2012. Australia’s Country Towns 2050: What Will a Climate Adapted Settlement Pattern Look Like? Gold Coast: NCCARF.

Blunt, A. and R. Dowling. 2006. Home. London: Routledge.

Brown, K. 2014. Global environmental change I: a social turn for resilience? Progress in Human Geography 38:1, 107-117.

Bulkeley, H. and S. Moser. 2007. Responding to climate change: governance and social action beyond Kyoto. Global Environmental Politics 7:2, 1-10.

Bulkeley, H. and Newell, P. 2010. Governing Climate Change. London: Routledge.

Bulkeley, H. and R. Tuts. 2013. Understanding urban vulnerability, adaptation and resilience of climate change. Local Environment 18, 646-662.

Caruana, C. 2010. Picking up the pieces: family functioning in the aftermath of natural disaster. Family Matters 84, 79-88.

Cox, R. 2013. House/work: home as a space of work and consumption. Geography Compass 7:12, 821-831.

Cupples, J. 2007. Gender and Hurricane Mitch: reconstructing subjectivities after disaster. Disasters $31: 2,155-175$.

Davidson, M. 2010. Sustainability as ideological praxis: the acting out of planning’s master signifier. City 14, 390-405.

Dowling, R. and E. Power. 2011. Beyond McMansions and Green Homes. In Material Geographies of Household Sustainability, ed. R. Lane and A. Gorman-Murray. Aldershot: Ashgate.

Eakin, H. 2006. Weathering Risk in Rural Mexico: Climatic, Institutional, and Economic Change. Tucson: University of Arizona Press.

Eriksen, C. 2013. Gender and Wildfire: Landscapes of Uncertainty. New York: Routledge. Eriksen, C. and N. Gill. 2010. Bushfire and everyday life: examining the awareness-action 'gap’ in changing rural landscapes. Geoforum 41:5, 814-825.

Ford, J. D., B. Smit, J. Wandel, M. Allurut, K. Shappa, H. Ittusarjuat, and K. Qrunnut. 2008. Climate 
change in the Arctic: Current and future vulnerability in two Inuit communities in Canada.

Geographical Journal 174, 45-62.

Fordham, M.H. 1998. Making women visible in disasters: problematising the private domain.

Disasters 22:2, 126-143.

Gibson, C., C. Farbotko, N. Gill, L. Head, and G. Waitt. 2013. Household Sustainability: Challenges and Dilemmas in Everyday Life. Cheltenham: Edward Elgar.

Gibson-Graham, J-K. and G. Roelvink. 2010. An economic ethics for the Anthropocene. Antipode 41, 320-346.

Gorman-Murray, A. 2011. Economic crises and emotional fallout: work, home and men’s sense of belonging in post-GFC Sydney. Emotion, Space and Society 4:4, 211-220.

Gregson, N. 2007. Living With Things: Ridding, Accommodation, Dwelling. Wantage: Sean Kingston. Head, L., Atchison, J. Gates, A. and Muir, P. 2011. A fine-grained study of the experience of drought risk and climate change among Australian wheat farming households. Annals of the Association of American Geographers 101:5, 1089-1108.

Head, L., M. Adams, H. McGregor, and S. Toole. 2013. Australia and Climate Change. WIREs Climate Change doi: 10.1002/wcc.255.

Howitt R., O. Havnen, and S. Veland. 2012. Natural and unnatural disasters: Responding with respect for Indigenous rights and knowledges. Geographical Research 50: 47-59.

Hulme, M. 2010. Learning to live with recreated climates. Nature and Culture 5, 117-22.

Kaika, M. 2005. City of Flows: Modernity, Nature, and the City. New York: Routledge.

Kates, R. W., W. R. Travis, and T. J. Wilbanks. 2012. Transformational adaptation when incremental adaptations to climate change are insufficient. Proceedings of the National Academy of Sciences 109: 7156-61.

Klocker, N., C. Gibson and E. Borger. 2012. Living together, but apart: material geographies of everyday sustainability in extended family households. Environment and Planning A 44: 2240-59. MacKinnon, D. and K.D. Derickson. 2013. From resilience to resourcefulness: a critique of resilience policy and activism. Progress in Human Geography 37:2, 253-270.

Martin, R. 2002. Financialization of Daily Life. Temple University Press. 
McLain, R.J., P.T. Hurley, M.R. Emery and M.R. Poe. 2014. Gathering “wild” food in the city: rethinking the role of foraging in urban ecosystem planning and management. Local Environment 19:2, 220-240.

Methmann, C. and D. Rothe. 2012. Politics for the day after tomorrow: the logic of apocalypse in global climate politics. Security Dialogue 43:4, 323-344.

Miller, F., H. Osbahr, E. Boyd, F. Thomalla, S. Bharwani, G. Ziervogel, B. Walker, J. Birkmann, S. Van der Leeuw, J. Rockström, J. Hinkel, T. Downing, C. Folke, and D. Nelson. 2010. Resilience and vulnerability: complementary or conflicting concepts? Ecology and Society 15:3, 11.

Morrice, S. 2013. Heartache and Hurricane Katrina: recognising the influence of emotion in postdisaster return decisions. Area 45:1, 33-39.

O’Neill, S.J. and J. Handmer. 2012. Responding to bushfire risk: the need for transformative adaptation. Environmental Research Letters 7:1, doi:10.1088/1748-9326/7/1/014018

Park S.E., N. Marshall, E. Jakku, A. Dowd, S. Howden, E. Mendham, and A. Fleming. 2012. Informing adaptation responses to climate change through theories of transformation. Global Environmental Change 22, 115-26.

Pickerill, J. and P. Chatterton. 2006. Notes towards autonomous geographies: creation, resistance and self-management as survival tactics. Progress in Human Geography 30:6, 730-746.

Pielke Jr, R., G. Prins, S. Rayner, and D. Sarewitz. 2007. Climate change 2007: Lifting the taboo on adaptation. Nature 445: 597-98.

Pink, S. 2012. Situating Everyday Life: Practices and Places, London: Sage. Power, E.R. 2005. Human-nature relations in suburban gardens. Australian Geographer 36: 39-53. Preston, B.L. 2013. Local path dependence of U.S. socioeconomic exposure to climate extremes and the vulnerability commitment. Global Environmental Change 23:4, 719-732.

Prior, T. and C. Eriksen. 2013. Wildfire preparedness, community cohesion and socio-ecological systems. Global Environmental Change 23:6, 1575-1586.

Proudley, M. 2008. Fire, families and decisions. Australian Journal of Emergency Management 23:1, $37-43$. 
Reid, L., P. Sutton, and C. Hunter. 2009. Theorizing the meso-level: the household as a crucible of pro-environmental behavior. Progress in Human Geography 34: 309-327.

Sevoyan, A, G. Hugo, H. Feist, G. Tan, K. McDougall, Y. Tan and J. Spoehr. 2013. Impact of climate change on disadvantaged groups. Gold Coast, NCCARF.

Shove, E. 2012. The shadowy side of innovation: unmaking and sustainability. Technology Analysis \& Strategic Management 24: 363-375.

Shove, E. and G. Walker. 2010. Governing transitions in everyday life. Research Policy 39:4, 471-76. Solomon, S., G-K. Plattner, R. Knutti, and P. Friedlingstein. 2009. Irreversible climate change due to carbon dioxide emissions. Proceedings of the National Academy of Sciences 106, 1704-09.

Stafford Smith M., L. Horrocks, A. Harvey, and C. Hamilton. 2011. Rethinking adaptation for a $4^{\circ} \mathrm{C}$ world. Philosophical Transactions of the Royal Society A 369: 196-21.

Strengers, Y. and Maller, C. 2012. Materialising energy and water resources in everyday practices: Insights for securing supply systems. Global Environmental Change 22:3, 754-763.

Waitt, G., P. Caputi, C. Gibson, C. Farbotko, L. Head, N. Gill, and E. Stanes. 2012. Sustainable household capability: which households are doing the work of environmental sustainability? Australian Geographer 43, 51-74.

Whittaker, J., J. Handmer, and D. Mercer. 2012. Vulnerability to bushfires in rural Australia. Journal of Rural Studies 28:2, 161-173.

Whittle, R., M. Walker, W. Medd and Mort, M. 2012. Flood of emotions: emotional work and longterm disaster recovery. Emotion, Space and Society 5:1, 60-69.

Correspondence: Department of Geography and Sustainable Communities, University of Wollongong, Wollongong NSW 2522, Australia e-mail: cgibson@uow.edu.au (Gibson); lhead@uow.edu.au (Head); cac900@uowmail.edu.au (Carr). 